SHS Web of Conferences 10, 00002 (2014)

DOI: $10.1051 /$ shsconf $/ 20141000002$

C Owned by the authors, published by EDP Sciences, 2014

\title{
Communication as an intergenerational Barrier
}

\author{
T. Adamkova and V. Dankova \\ University of Hradec Kralove, Czech Republic
}

\begin{abstract}
In the article we use the data from specific research entitled "Media Education in the Family" and conducted by the Department of Social Pedagogy, College of Education, University of Hradec Králové, in 2012. The survey focused on mapping the state of media education in the contemporary Czech families. Specifically, we asked families with children at the age from six to fifteen. The data collection was conducted by questionnaire method. Our group of researchers created two different forms of questionnaires, the first one for parents and the second one, which was modified into appropriate form for children. Questionnaires were given to both parents (if they lived both in the household) and to one child in each family. The children were divided into groups according to their age: the first age group from 6 to 8 years, the second group from 9 to 11 years and the third group from 13 to 15 years. Into these age categories (quotas) were included families with a child at a given age. Parents separately completed a questionnaire. The researchers had to do a controlled interview with children due to possible misunderstanding of the questions by the youngest respondents. Then the researchers filled in answers from children to the appropriate questionnaire. Totally 1, 306 questionnaires were received from parents and 566 from children after exclusion of improperly completed questionnaires.

All data relate to families in Czech society, but we think that many of the characteristics could occur in families from other countries as well. This is caused mainly by a global expansion in electronic media.
\end{abstract}

\section{Czech families and an intergenerational communication}

We would like to focus on changes in intergenerational communication and on the deepening communication barrier among contemporary Czech generations. Arising problems in intergenerational communication are influenced by the changing interconnection of generations in the Czech families. The number of multigenerational living, which means cohabitation of grandparents, parents and their children, has been decreasing in recent years. On the contrary, the number of two generation families (= parents and their children) has been increasing.

There has been a limitation of communication topics among different age groups recently. We consider that the value of positive family relationships has weakened. Children prefer development of the relationship with peers and they (children) communicate with peers more than with their parents. This kind of communication is simplified and accelerated. Children are not limited only to personal meetings with peers but they can satisfy their need to entrust immediately by using any type of electronic media. They (children) can immediately tell anyone else any necessary information, even if they are at home only with their parents.

This is an Open Access article distributed under the terms of the Creative Commons Attribution License 4.0, which permits unrestricted use, distribution, and reproduction in any medium, provided the original work is properly cited. 


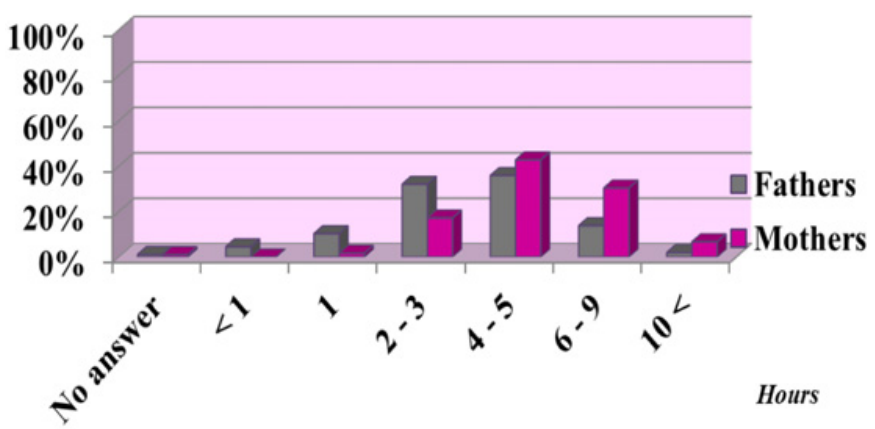

Graph 1. How much time do you spend with your children on average per day on weekdays?

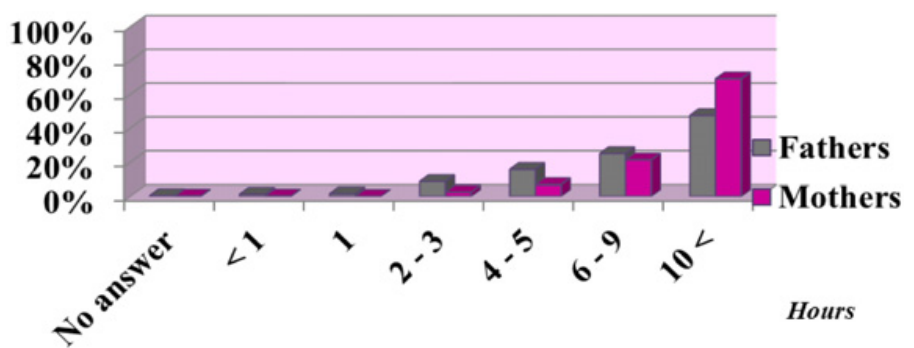

Graph 2. How much time do you spend with your children on average per day at weekends?

The lack of time due to work, hobbies and other activities has become a fundamental problem. (Graph 1, Graph 2.)

On weekdays mothers and fathers usually spend from four to five hours per day with their children. The difference is that the second most frequently marked answer by mothers was time from six to nine hours and by fathers - time from two to three hours per day on weekdays.

The most frequent answer to the question "How much time do you spend with your children on average per day at weekends?" was the time period from ten hours. Mothers marked this answer significantly more frequently than fathers. The answers by fathers were equally stratified into other options.

Parents are not personally able to ensure the need of suitable and meaningful stimulation due to their lack of time. Parents satisfy the physiological needs of their child during the first months of child's life. After this period the parents are replaced by electronic media. The electronic media, at least minimally, satisfy psychological and social needs by "speaking" to children. It is obvious that this substitution of family function is not sufficient. If a child doesn't grow up in a stimulating environment, it can have negative consequences for its future development.

\section{Electronic media and their influence on communication among generations}

Furthermore, we would like to focus mainly on the issue of electronic media and their influence on the communication between parents and their children. The unprecedented technological advance in recent years has been one of the causes of greater communication barrier that has developed between parents and their children, who get acquainted with the latest electronic media since an early age. On 
Int. Conf. SOCIETY. HEALTH. WELFARE.

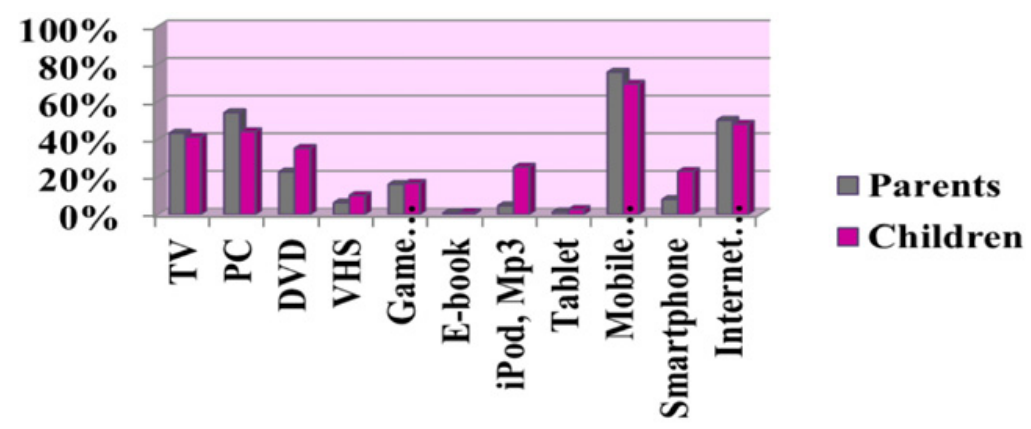

Graph 3. Does your child have these equipments only for personal use anywhere? Do you have these equipments only for personal use anywhere?

the contrary, this technological heyday could also be the cause of weaker orientation of parents in new media technologies.

Our research included questions about children's electronic equipments. Researchers asked children as well as parents. (Graph 3.)

Approximately half of the responded children have for personal use a computer and the Internet access. The technological development is rapid. There was certainly a lower rate of children who possessed a personal computer, who were able to easily access the Internet or who had their own mobile phone, when our generation attended primary school. This reality is obvious, when we look on the diagram number three, which shows that an absolute majority of children have their own mobile phone nowadays (approximately 70\%). There is a great difference in the number of answers marked by children and by parents to the question "Does a child have a smartphone?". We assume that the cause of this difference can be a weak orientation of parents in the field of new media. Parents consider the smartphone as the normal mobile phone.

Different number of answers to the question "Does a child have an iPod or mp3 player?" is a consequence of improperly assigned question included in the questionnaires for parents. In questionnaires for parents, was not included a question "Does your child have mp3 player?".

Different communication elements. We suppose that the contradictions among current generations are often caused by utilization of different communication elements. Among members of the youngest generation especially popular is a virtual communication. It is obvious that the virtual communication differs from a classic face-to-face communication in many ways. Abbreviated words and sentences, an inability to express feelings and request for assistance or an inability to listen and understand the other person are the elements in communication of the youngest generation, which create the communication barrier between parents and their children, as well as between children and their grandparents. Neither parents nor grandparents have communicated with their children or their grandchildren via the Internet in almost all cases, and therefore they have not adopted the same communication elements their children or their grandchildren. Unfortunately, each generation has developed a different way of communication. Therefore we think that many parents do not understand the importance and significance attributed to the virtual communication by their children. (Graph 4, Graph 5.)

$90 \%$ of children answered, that heky can easily access the Internet either in school, at home or at grandparents.

$70 \%$ of children answered to the question "What do you do on the computer most often?" that they play games and $40 \%$ of children answered that they communicate with friends via the Internet, especially via social networks like Facebook. It is necessary to mention that even playing games is connected with virtual communication. Children could give up to three answers within this question. The percentage rate of answers noted in the option "communication with friends" can seem a bit low. But it is necessary 


\section{SHS Web of Conferences}

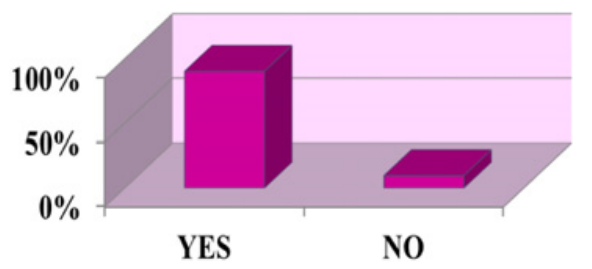

Graph 4. Do you have an access to the Internet anywhere?

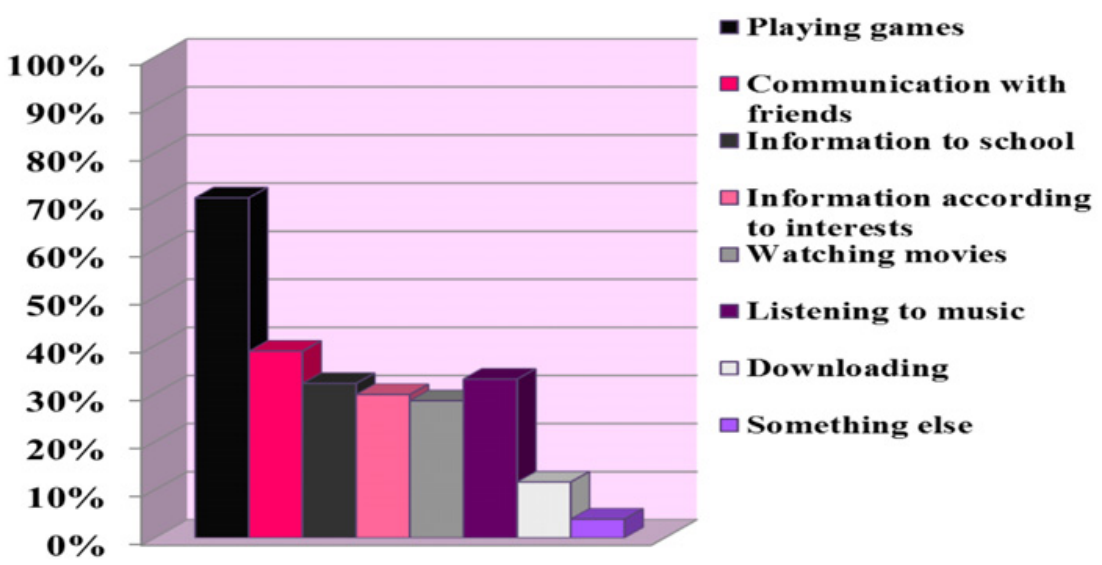

Graph 5. What do you do on the computer most often?

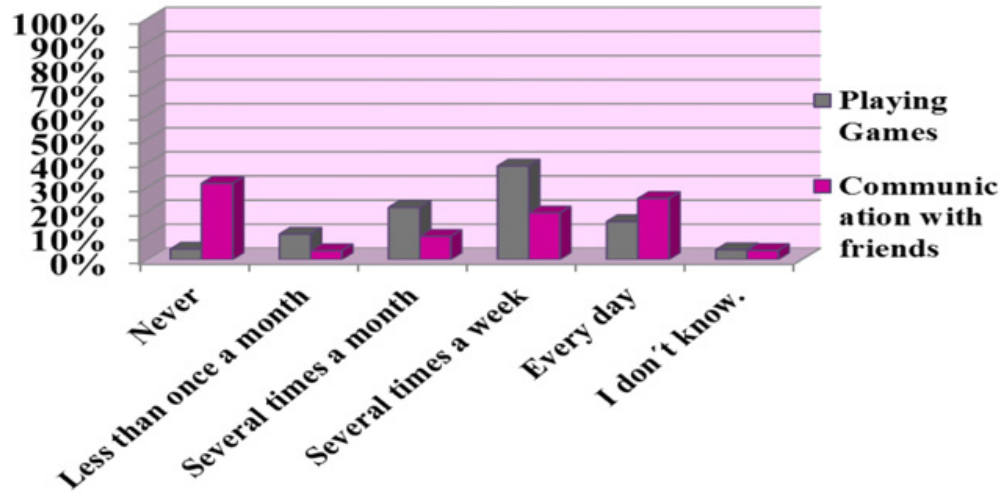

Graph 6. How often does your child do these activities on the computer?

to understand that most of communication via social networks occurs among adolescents. Two age categories that encompass younger children from 6 to 12 years are represented in our research. Children from the age of 13 to the age of 15 pose only one third of the population sample.

Children answered very often that they played computer games as Graph 5 shows. One of the inseparable components of online gaming is virtual communication. Thus we asked parents, how often 
Int. Conf. SOCIETY. HEALTH. WELFARE.

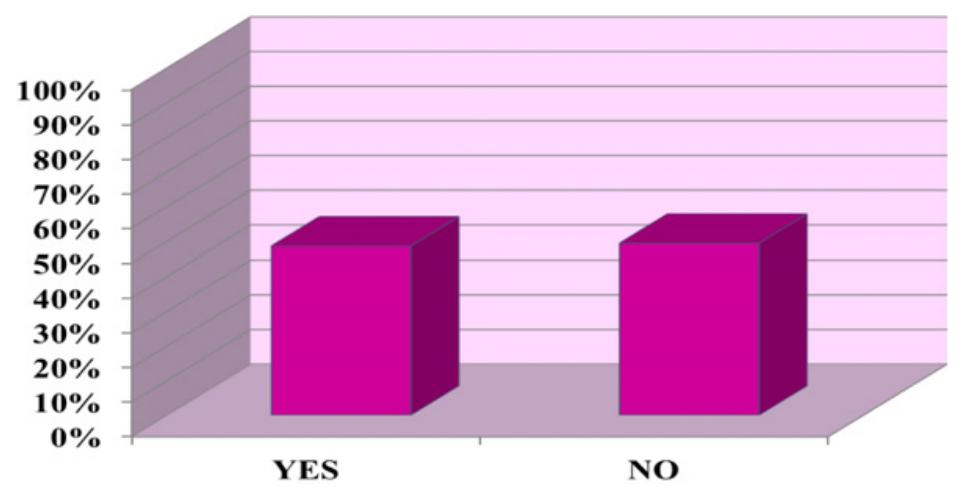

Graph 7. Does your child play online computer games?

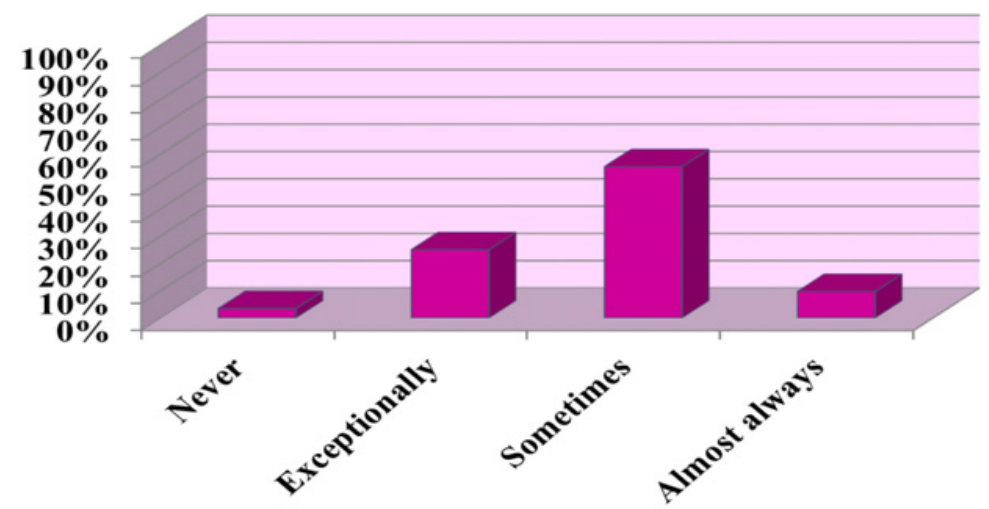

Graph 8. How do you usually spend your weekends? - Our family visit the relatives.

their children play computer games and how often use a virtual way to communicate with friends. 30\% of parents answered that their children do not use the virtual way of communication. Results are again influenced by the representation of two younger age categories within our research. On the other hand, other $25 \%$ of parents answered that their children use the virtual means of communication every day. Additional $20 \%$ of parents also admitted that their children communicate via the Internet several times a week. In our opinion, the number of children using virtual way of communication is quite high. In total, there are $45 \%$ of children who use virtual means of communication at least several times a week, which we consider as a quite significant indicator.

Other question for parents focused $\mathrm{n}$ online computer games. (Graph 7.)

Playing computer games is a widespread activity among children. And even parents, in approximately $50 \%$ of answers, state that their children play online computer games.

Several possible variants of answers were given. In terms of the orientation of our issue we concentrated on the possibility that a family goes on common trips to visit their relatives at weekends. We assume that parents with their children visit mostly grandparents. More than 50\% of parents stated that they go on such trips only time to time (sometimes). This reality can contribute to the deepening of communication barrier between grandchildren and grandparents. (Graph 8.) 


\section{SHS Web of Conferences}

\section{Conclusion}

Swiftly changing world of the communication media has an undisputable influence on the mutual communication across generations and it is one of the causes of everyday misunderstanding among the different age groups. And therefore a resumption of the active and positive communication between parents and their children or between children and their grandparents could become one of the aspects of rediscovering the mutual understanding among different age groups.

\section{References}

Media Education in the Family. - University of Hradec Králové, 2012 